\title{
Antibiotic Susceptibility Pattern and Distribution of Virulence Factors Among Klebsiella pneumoniae Isolated from Healthy Volunteers

\author{
Amine Dalir ${ }^{1,2}$, Shabnam Razavi ${ }^{1,2 *}$ iD , Malihe Talebi ${ }^{1,2}$ iD , Faramarz Masjedian Jazi ${ }^{1,2}$ iD,
} Abed Zahedi Bialvaei ${ }^{1}$ iD, Maryam Mirshekar ${ }^{2}$ iD, Vahid Lohrasbi $^{2}$ iD
}

1. Microbial Biotechnology Research Center, Iran University of Medical Sciences, Tehran, Iran

2. Department of Microbiology, Faculty of Medicine, Iran University of Medical Sciences, Tehran, Iran

$\underline{10.30699 / i j m m .15 .6 .676}$

\section{ABSTRACT}

Background and Aim: The healthy people's fecal flora in the community represents a large potential reservoir. Therefore, the current study aimed to detect antibiotic resistance patterns and virulence factors in Klebsiella pneumoniae isolated from healthy volunteers' feces.

Materials and Methods: Three hundred and fifty stool specimens were collected from sales rep healthy individuals referring to the Northwest Tehran Health Centers to get a health card. Bacterial isolation, identification, and antimicrobial susceptibility testing were conducted according to the routine instructions. In addition, polymerase chain reaction (PCR) was used to detect the genetic factors responsible for producing extended-spectrum $\beta$-lactamases (ESBLs: SHV, TEM, and CTX-M) blaKPC and other virulence genes.

Results: Among fecal samples analyzed, 60 (17.1\%) K. pneumoniae were isolated. The results demonstrated that the highest resistance rate was related to piperacillin-tazobactam $(n=25,41.6 \%)$, followed by and meropenem $(n=17,28.8 \%)$ and cotrimoxazole $(n=11,18.3 \%)$, respectively. Also, all strains were susceptible to amikacin, gentamicin, and imipenem. The PCR results of the virulence gene showed that $95 \%(n=57)$ of isolates were positive for fimH gene, $93.33 \%(n=56)$ for $B s s S$ gene, $27(45 \%)$ for $r m p A$ gene. The PCR results for antibiotic resistance genes showed that $41.66 \%(n=25)$ had blaTEM gene, $38.33 \%(n=23)$ blaCTX-M gene, 35\% $(n=21)$ blaSHV gene and $3.33 \%(n=2)$ isolates had blaKPC gene, and none of these isolates carried magA gene.

Conclusion: Antibiotic resistance was common among $K$. pneumoniae isolated from healthy volunteers' feces who participated in this study. Transmission of resistant bacteria and plasmids through oral-fecal sources threats to the public, which could complicate treatment options for community-acquired infections caused by K. pneumoniae.

Keywords: Antibiotic resistance, ESBL, Klebsiella pneumoniae, Virulence genes

Received: 2021/09/12; Accepted: 2021/11/10; Published Online: 2021/12/08

\begin{tabular}{|c|c|c|c|c|}
\hline \multicolumn{3}{|c|}{ Received: 2021/09/12; } & Accepted: 2021/11/10; & Published Online: 2021/12/08 \\
\hline \multirow{2}{*}{\multicolumn{2}{|c|}{ Corresponding Information: }} & Shabnam Razavi, Pr & Assistant professor in Medical Bi & chnology, Department of Microbiology, Faculty of Medicine, Iran \\
\hline & & University of Medic & ciences, Tehran, Iran Tel/fax: +98 & 86703473, Email: razavi.sh@iums.ac.ir \\
\hline (c) & & $\begin{array}{l}\text { is is an original open } \\
\text { istribution of the mat }\end{array}$ & $\begin{array}{l}\text { rticle distributed under the terms of } t \\
\text { in noncommercial usages with prope }\end{array}$ & $\begin{array}{l}\text { eative Com } \\
\text { tion. }\end{array}$ \\
\hline
\end{tabular}

Use your device to scan and read the article online

Dalir A, Razavi S, Talebi M, Masjedian Jazi F, Zahedi Bialvaei A, Mirshekar M et al . Antibiotic Susceptibility Pattern and Distribution of Virulence Factors Among Klebsiella pneumoniae Isolated from Healthy Volunteers. Iran J Med Microbiol. 2021; 15 (6) :676-683

\section{Download citation: BibTeX | RIS | EndNote | Medlars | ProCite | Reference Manager | RefWorks}

\section{Send citation to: $* \underline{\text { Mendeley }} \mathbf{Z}_{\text {Zotero }} \mathbb{H}_{\text {RefWorks }}$}

\section{Introduction}

Klebsiella pneumoniae is an opportunistic Gramnegative bacterium associated with hospitals- and community-acquired infections. $K$. pneumoniae has evolved into two particular pathotypes: classical and hypervirulent $K$. pneumoniae (1). Classical K. pneumoniae has been called a superbug dependent on its acquisition of different antimicrobial resistance genes and is basically responsible for hospital-acquired infections (2). Hypervirulent strains are more virulent than classical strains and are initially described to cause community-acquired infections (3).

The increasing global prevalence of antimicrobialresistant bacteria, both in the hospital and in the community, jeopardizes the ability to effectively treat patients (4). Because these bacteria often show 
multidrug resistance (MDR) phenotypes, treatment options are severely limited (5). Therefore, it can be assumed that patients with serious infections will soon no longer be treatable with existing antimicrobial drugs. This resistance is mainly because of plasmids containing extended-spectrum $\beta$-lactamase (ESBL). ESBL enzymes in $K$. pneumoniae are mainly consisted of two types of enzymes SHV and TEM encoded by the plasmid, and were often associated with nosocomial outbreaks (6). Furthermore, there is an increasing rate of $K$. pneumoniae strains producing CTX-M type, and they are now considered to be the primary ESBL producers that are almost always associated with community-acquired infections $(7,8)$. Because the genes are simply spread via plasmid among the Enterobacteriaceae family, they can simplify the transmission of resistance to beta-lactams and other antibiotics (9). Moreover, the pathogenicity of $K$. pneumoniae is because of diverse virulence factors that empower the bacteria to conquer innate host immunity and to cause infection in a host $(9,10) . K$. pneumoniae virulence factors are lipopolysaccharides, capsule, the ability of biofilm formation, hyper-mucoviscosity, iron acquisition systems, serum resistance, and adhesins $(11,12)$.

K. pneumoniae with potency in acquiring antimicrobial resistance genes and pathogenicity can be asymptomatically carried in the intestinal tract, nose, throat, and skin of healthy individuals. Studies of the gut flora of humans and animals give a more precise picture of the entire burden of antimicrobial resistance in society than data based on pathogenic isolates. As a matter of fact, the study of gut flora has shown that they may act as a reservoir for plasmids harboring antibiotic resistance genes, especially ESBL $(13,14)$. Moreover, drug resistance surveillance has reported that asymptomatic carriers in the population are mostly colonized with resistant bacteria, resulting in the infection $(15,16)$. So the study of gut flora is helpful in the understanding and monitoring of resistance mediated selection in the community (17). In addition, fecal carriage of antibiotic-resistant $K$. pneumoniae can be a community reservoir and lead to outbreaks. The current study was aimed to detect the antibiotic resistance pattern, the genetic determinants responsible for ESBL production (SHV, TEM, and CTX-M), carbapenem resistance (blaKPC), and other virulence genes [magA (Mucoviscosity associated gen), rmpA (hypermucoviscosity), fimH (fimbriae gene), BssS (biofilm formation)] in $K$. pneumoniae isolated from healthy volunteer's feces.

\section{Material and Methods}

\section{Sample Collection and Questionnaire}

The cross-sectional descriptive study was conducted among 350 fresh stool samples randomly selected from healthy volunteers (healthy volunteers to get a health card) submitted to the Northwestern Tehran Health Center between February and October 2018. A questionnaire was prepared for every volunteer who participated in the study to collect data regarding name, gender, age, medical history (History of hospitalization or antacid and antibiotic intake), dietary habits (cheese, yogurt, milk, chicken, or meat consumption), and personal hygiene habits. People who had a history of using antibiotics, probiotics, and prebiotics and people with a history of chronic gastrointestinal infections were excluded from the research. The stool samples were cultured on MacConkey agar plates (Merck, Germany) and incubated at $37^{\circ} \mathrm{C}$ for 24 hours. The identifying process for $K$. pneumoniae isolates carried out using Gram staining and biochemical testing (methyl red, indole, citrate, vogus-prauskaur, urease, and mobility).

\section{Susceptibility Testing}

An antimicrobial susceptibility testing was done for each pure isolation by Kirby-Bauer disc diffusion method following the Clinical and Laboratory Standard Institute guidelines (2018). The following antibiotics were used: ceftriaxone $(30 \mu \mathrm{g})$, piperacillin tazobactam $(100 \mu \mathrm{g})$, co-trimoxazole $(1.25 \mu \mathrm{g})$, amikacin (30 $\mu \mathrm{g})$, cefotaxime $(30 \mu \mathrm{g})$, ciprofloxacin $(5 \mu \mathrm{g})$, ceftazidime $(30 \mu \mathrm{g})$, cefipime $(30 \mu \mathrm{g})$, meropenem $(10 \mu \mathrm{g})$, imipenem $(10 \mu \mathrm{g})$, and gentamicin $(10 \mu \mathrm{g})$. Escherichia coli ATCC 25922 was used as negative controls (18).

MIC was performed to detect susceptibility to imipenem, meropenem, ciprofloxacin and ceftriaxone using E-test strip (Liofilchem, Italy), following the manufacture's protocol. Briefly, Mueller-Hinton agar plates (Merck, Germany) were inoculated with $K$. pneumoniae strain suspensions adjusted to $0.5 \mathrm{McF}$ arland standard turbidity and E-test strips were used. The MIC for each isolate was measured by reading the value at the point of intersection of the inhibition zone with the point on the scale of the E-test strip.

\section{Analysis of Resistance and Virulence Genes using PCR Method}

The extraction of bacterial DNA was performed by the boiling method (19). First, a colony of a bacterial isolate was added to $20 \mu \mathrm{L}$ of tissue buffer consisting of $0.05 \mathrm{M} \mathrm{NaoH}+0.25 \%$ SDS and incubated for 10 minutes at $95^{\circ} \mathrm{C}$. After incubation, the mixture was centrifuged at $13,000 \mathrm{~g}$ for one minute, and $180 \mu \mathrm{L}$ of Milli-Q water was added. The extracted DNA was frozen at $-20^{\circ} \mathrm{C}$ for long-term storage.

The designed oligonucleotide sequences utilized to amplify fragments of the target genes are shown in Table 1. Polymerase Chain Reaction (PCR) was performed in a total volume of $25 \mu \mathrm{L}$ containing $12.5 \mu \mathrm{L}$ of PCR Master Mix x2 (Amplicon, Denmark), $1 \mu \mathrm{L}$ of each Forward and Reverse primer, $1 \mu \mathrm{L}$ of DNA template, $9.5 \mu \mathrm{L}$ sterile deionized distilled water, then DNA 
amplification was carried out with the thermocycler (Thermo Scientific, USA). Escherichia coli ATCC 25922,
K. pneumoniae Strains ATCC 700603, and ATCC 7881 were used as controls.

Table 1. The sequences of primers used in this study

\begin{tabular}{|c|c|c|c|c|}
\hline Genes & Sequence $5^{\prime}$ to $3^{\prime}$ & Product size & Sources & $\begin{array}{c}\text { Annealing } \\
\text { temperature }\end{array}$ \\
\hline \multirow[t]{2}{*}{ magA } & GCCAGTCCGAAAGTGAACGA & 162 & This study & 56 \\
\hline & TGCCAACAATTCCCGTTTCTG & & & \\
\hline \multirow[t]{2}{*}{ RmpA } & TTCAGGGAAATGGGGAGGGT & 250 & This study & 60 \\
\hline & TTGCAGCACTGCTTGTTCCT & & & \\
\hline \multirow[t]{2}{*}{ fimH } & ATCGTTAATCGCGGTGCTGA & 274 & This study & 54 \\
\hline & GGAGGCGGTATTGGTGAAGA & & & \\
\hline \multirow[t]{2}{*}{ BssS } & AGCTACGATGCGCTGATGTT & 148 & This study & 58 \\
\hline & САATCTTCGCAATGCCTGCT & & & \\
\hline \multirow[t]{2}{*}{ Blakpc } & GCCGTCTAGTTCTGCTGTCT & 141 & This study & 60 \\
\hline & CGGTATCCATCGCGTACACA & & & \\
\hline \multirow[t]{2}{*}{ blaCTXM } & CGCGTGATACCACTTCACCT & 77 & This study & 60 \\
\hline & GCTGTCGCCCAATGCTTTAC & & & \\
\hline \multirow[t]{2}{*}{ blaSHV } & ACAGCTGGCTTTCGCTTAGT & 85 & This study & 60 \\
\hline & АTCTCCCTGTTAGCCACCCT & & & \\
\hline \multirow[t]{2}{*}{ blaTEM } & CGTGTCGCCCTTATTCCCTT & 480 & This study & 60 \\
\hline & CTCCGGTTCCCAACGATCAA & & & \\
\hline
\end{tabular}

The PCR amplification consisted of an initial denaturation at $95^{\circ} \mathrm{C}$ for $5 \mathrm{~min}$, followed by 40 cycles of denaturation at $95^{\circ} \mathrm{C}$ for $40 \mathrm{~s}$, annealing for $40 \mathrm{~s}$ at temperatures specified for each primer, and extension at $72^{\circ} \mathrm{C}$ for $30 \mathrm{~s}$. This was followed by a final extension step at $72^{\circ} \mathrm{C}$ for 5 minutes. The PCR products were electrophoresed using $1 \%$ agarose gel and visualized by a gel documentation system.

\section{Results}

The stool samples of 350 healthy individuals were collected from Northwestern Tehran Health Centers during a period of 8 months, from February 2018 to October 2018. The specimens were examined for microbial and biochemical tests in the laboratory of the Medical School of Iran University of Medical Sciences for the presence of $K$. pneumoniae. Of the 350-stool sample, all belonging to male individuals, only 60 isolates were identified as K. pneumoniae. In this study, the age range was $20-42$ years, $67 \%$ were under 30 . About $49 \%$ of these people also had nutrition-related occupations (Figure 1).

Among $K$. pneumoniae isolates, the highest resistance rate belonged to piperacillin-tazobactam (41.6\%, $n=25)$, meropenem $(28.8 \%, n=17)$ and cotrimoxazole $(18.3 \%, n=11)$, followed by cefotaxime $(8.3 \%, n=5)$, ceftazidime, ceftriaxone $(6.6 \%, n=4)$, cefepime $(6.6 \%, n=4)$ and ciprofloxacin $(1.6 \%, n=1)$, respectively. The MIC of meropenem-resistant isolates was above $4(\mu \mathrm{g} / \mathrm{mL})$, and for ceftriaxone, resistance was above $12(\mu \mathrm{g} / \mathrm{mL})$, the only ciprofloxacin-resistant isolate was above $8(\mu \mathrm{g} / \mathrm{mL})$. Figure 2 shows the antibiotic susceptibility of the isolates. 


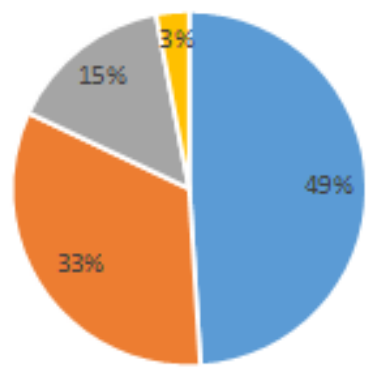

- Nutritional depen dent = Official " Service " Lifeguard

Figure 1. Occupations of the study subjects

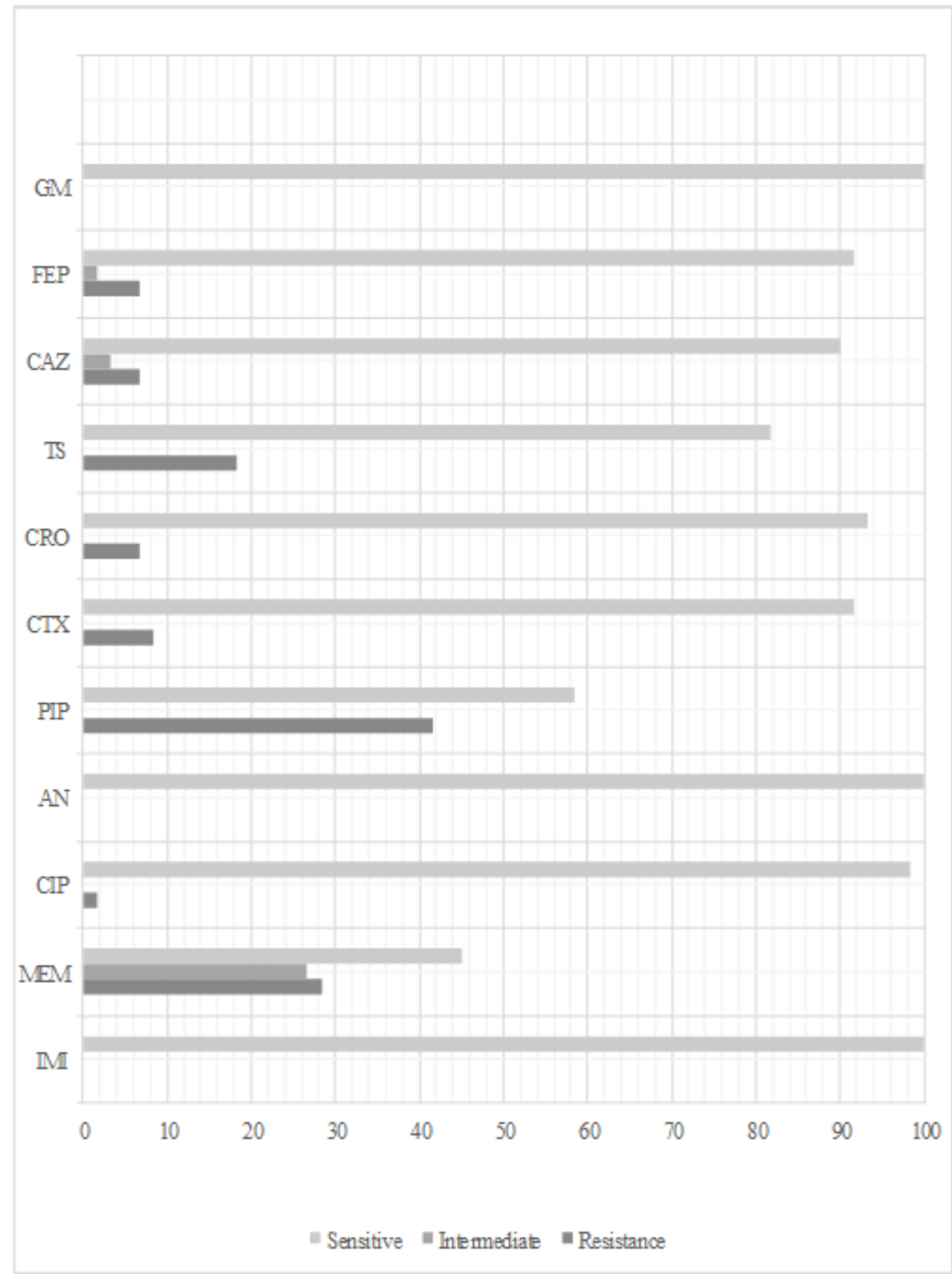

Figure 2. Percentage of antibiotic susceptibility in Klebsiella pneumoniae isolates 
Among 60 isolates of $K$. pneumoniae, $95 \%(n=57)$ of isolates had fimH, $93.33 \%(n=56)$ had BssS, $45 \%(n=27)$ had $r m p A, 41.66 \%(n=25)$ had blaTEM, 38.33\% $(n=23)$ had blaCTX-M, 35\% $(n=21)$ had blaSHV and $3 \%(n=2)$ had blaKPC, and none of these isolates carried magA gene (Figure 3). Out of $60 \mathrm{~K}$. pneumoniae, 53 (88\%) isolates had fimH and $B s s S$ genes simultaneously. MDR was observed in $4(6.6 \%)$ cases of $K$. pneumoniae isolates. Out of MDR isolates, 3 had $\mathrm{fimH}$ and BssS genes.
Among all K. pneumoniae isolates, 28 (46.6\%) had blaCTX-M, blaSHV, and blaTEM, (ESBLS) genes, of which $11(18.3 \%)$ isolates belonged to patients in occupations related to the food industries. In addition, 21 (35\%) ESBL positive isolates showed resistance to beta-lactams. Also, 8 (13.3\%) isolates showed resistance to third-generation cephalosporins, of which 4 $(6.6 \%)$ isolates had both blaTEM and blaSHV genes.

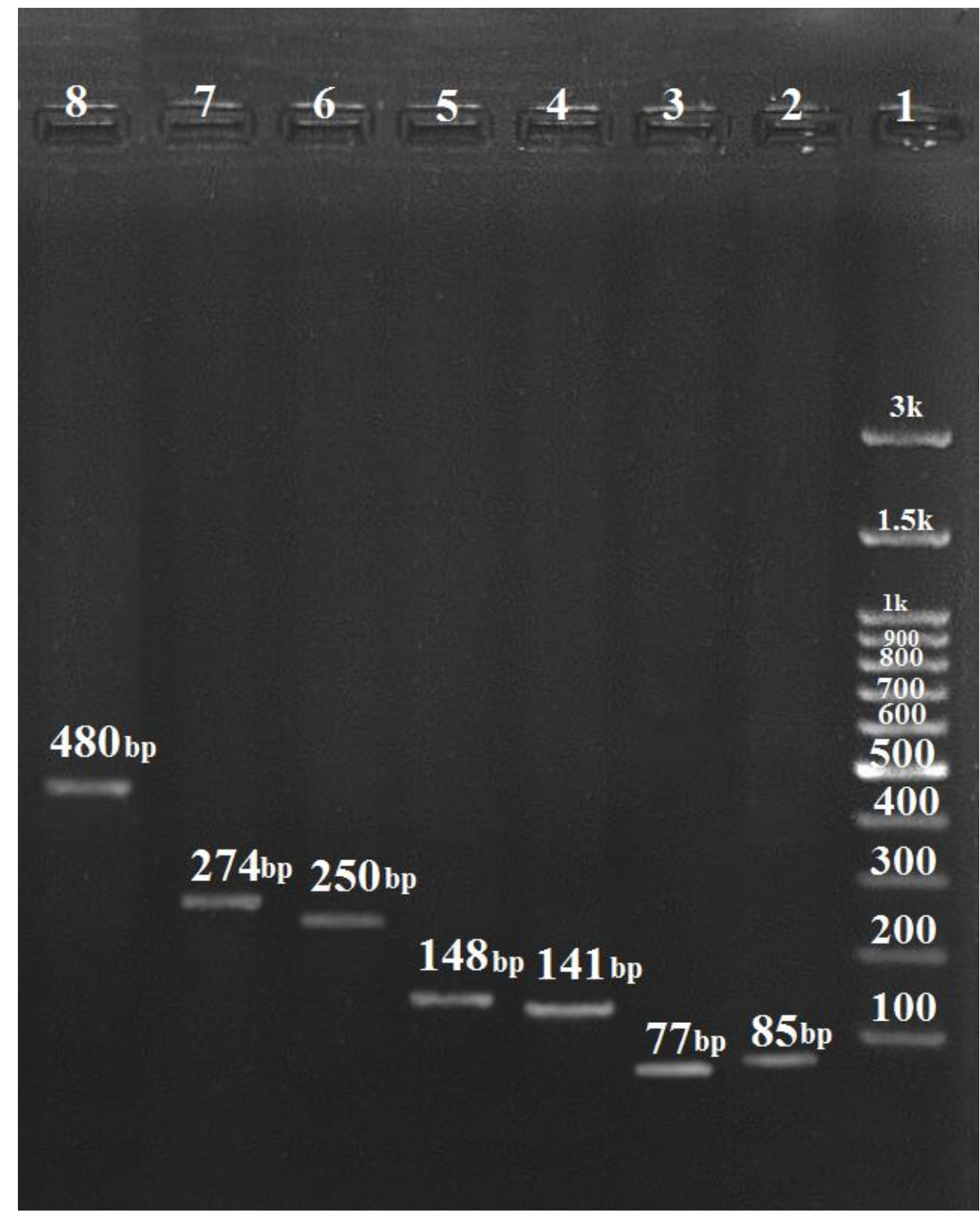

Figure 3. Gel electrophoresis results of virulence and antibiotic resistance genes - well 1: 100 bp DNA molecular marker, well 2: blaSHV, well 3: blaCTXM, well 4: blaKPC, well $5 \mathrm{BssS}$, well 6: rmpA, well 7: fimH, well 8: blaTEM genes

\section{Discussion}

In this study, $60 \mathrm{~K}$. pneumoniae isolates were identified in 350 stool samples obtained from comprehensive health examinations in Tehran, Iran. Our results confirm the high intestinal carriage of drug-resistant $K$. pneumoniae, in which the highest and lowest resistance rate belonged to piperacillintazobactam and ciprofloxacin, respectively. In addi- 
tion, the results showed that among all $K$. pneumoniae isolates, more than $90 \%$ carried $\mathrm{fim} \mathrm{H}$ and BssS genes.

The reported asymptomatic carriage rates of ESBL positive Enterobacteriaceae in the feces of community dwellers vary in Asian countries: 5.0\% in Japan (20), $40 \%$ in Thailand (21), and $50.6 \%$ in China (22). Most carriers were positive for CTX-M-type ESBL, which has nearly displaced other enzymes in Enterobacteriaceae, including SHV and TEM variants. We showed that the prevalence of blaTEM, blaCTX-M, and blaSHV genes among the studied isolates were 35\%, 38.33\%, and $41.66 \%$, respectively. However, Mansury et al. (2016) from Shiraz reported that the prevalence of blaTEM, blaCTX-M, and blaSHV genes among $38 \mathrm{ESBL}$ producing $K$. pneumoniae were $16 \%, 19 \%$, and $22.2 \%$, respectively (23). In their study, the highest levels of resistance were related to amoxicillin (100\%), cefotaxime $(50 \%)$, and gentamicin $(42.3 \%)$, and the lowest levels were related to meropenem (11.8\%), amikacin and imipenem (both 15.9\%). Asadpour et al., in 2016, determined the frequency of blaTEM and blaSHV genes in 34 broad-spectrum beta-lactamase producing K. pneumoniae by PCR (24). Of these, $40 \%$ of isolates carried blaTEM gene, and $23.07 \%$ had blaSHV gene. A Korean evaluation on stool samples of adults with comprehensive health examinations uncovered that from 109 fecal samples, only four blaSHV positive $K$. pneumoniae were identified (25). In another study carried out by Bing Lu et al., $22 \mathrm{~K}$. pneumoniae isolates were detected from among 4340 stool samples collected from patients with diarrhea (26). Their results showed that all isolates were susceptible to ciprofloxacin, gentamicin, cefotaxime, ceftriaxone, nalidixic acid, imipenem, cefepime; the highest resistance rate belonged to amoxicillinclavonate (100\%) and ampicillin (72.7\%) (26). The results showed that all strains were susceptible to imipenem, amikacin, and gentamicin, but little resistance was observed to ciprofloxacin, ceftriaxone and cefepime. In both studies, sensitivity to imipenem and gentamicin was observed, but cephalosporins may develop antibiotic resistance over time (8).

A study was performed by Candan and Aksöz (27) to evaluate the association among the genotypes of adhesins, mucoviscosity, capsules, carbapenem resistance, and other $K$. pneumoniae virulence factors. The OXA-48 and NDM-1 carbapenemase genes were detected in 33 and one from $50 \mathrm{~K}$. pneumoniae strains, respectively. Also, KPC was not detected in $K$. pneumoniae isolates. Although no significant difference was detected between susceptible and resistant strains because of the presence of virulence gene regions $(P \geq 0.05)$, virulence factors were more diverse in carbapenem-resistant isolates (27). In research by Rodríguez-Navarro et al. (28), the genetic content of commensal and clinical strains was investigated. Their results indicated that the replicon profile was comparative in both populations, except for HI1 (only in commensal strains) and $\mathrm{L}, \mathrm{M}, \mathrm{A} / \mathrm{C}$, and $\mathrm{N}$ (detected only in clinical strains). Although $F$ and $I 1$ were the most common replicons, only Incl1, sequence type 12 (ST12) was related to blaCMY-2 in both populations. Also, the discoveries from this investigation affirm that healthy people strains have lower virulence factors and antibiotic resistance and show a higher diversity of phylogenetic lineages (in E. coli) than infection-causing strains (28).

Biofilm formation is one of the reasons for the increasing antibiotic resistance. fimH and BssS genes are involved in biofilm formation and ultimately may have a role in increasing antibiotic resistance (29). The frequency of fimH and $\mathrm{rmpA}$ genes in a study by $\mathrm{El}$ Fertas-Aissani et al. in Algeria were $100 \%$ and $3.7 \%$, respectively (9). Another study was performed to evaluate fim $H$, and $r m p A$ genes among $K$. pneumoniae isolates in hospitalized patients from Babol, Iran, which their frequency was reported $86.1 \%$ and $10.8 \%$, respectively (30). Also, similar to our study, none of the isolates showed the $m a g A$ gene in the two recent reports.

\section{Conclusion}

In summary, although the sample was collected from healthy individuals, some antibiotic resistance genes were observed. We were able to isolate $K$. pneumoniae from 350 stool samples from adults that underwent a medical examination. Since the treatment of infections caused by this bacterium is associated with many limitations, there is a need for effective measures to prevent and control the infection and careful use of antibiotics to control the rise and spread of fecal carriage of antibiotic-resistant pathogens.

\section{Acknowledgment}

None.

\section{Funding}

None.

\section{Conflict of Interest}

There is no conflict of interest between the authors. 


\section{References}

1. Ghanavati R, Darban-Sarokhalil D, NavabMoghadam F, Kazemian H, Irajian G, Razavi S. First report of coexistence of AmpC betalactamase genes in Klebsiella pneumoniae strains isolated from burn patients. Acta Microbiologica et Immunologica Hungarica AMicr. 2017;64(4):455-62. [PMID] [DOI: 10.1556/030.64.2017.028]

2. Kuehn BM. "Nightmare" bacteria on the rise in US hospitals, long-term care facilities. JAMA. 2013;309(15):1573-4.

[DOI:10.1001/jama.2013.2922] [PMID]

3. Russo TA, Marr CM. Hypervirulent Klebsiella pneumoniae. Clinical microbiology reviews. 2019;32(3). [DOI:10.1128/CMR.00001-19] [PMID] [PMCID]

4. Zhanel GG, DeCorby M, Adam H, Mulvey MR, McCracken $M$, Lagace-Wiens $P$, et al. Prevalence of antimicrobial-resistant pathogens in Canadian hospitals: results of the Canadian Ward Surveillance Study (CANWARD 2008). Antimicrob Agents Chemother. 2010;54(11): 4684-93. [DOI:10.1128/AAC.00469-10] [PMID] [PMCID]

5. Ghanavati $R$, Kazemian $H$, Asadollahi $P$, Heidari $H$, Irajian G, Navab-Moghadam $F$, et al. Characterization of antimicrobial resistance patterns of Klebsiella pneumoniae isolates obtained from wound infections. Infect Disord Drug Targets. 2021;21(1):119-24. [PMID] [DOI: 10.2174/1871526520666200129124924]

6. Feizabadi MM, Delfani S, Raji N, Majnooni A, Aligholi $M$, Shahcheraghi $F$, et al. Distribution of bla TEM, bla SHV, bla CTX-M genes among clinical isolates of Klebsiella pneumoniae at Labbafinejad Hospital, Tehran, Iran. Microbial drug resistance. 2010;16(1):49-53.

[DOI:10.1089/mdr.2009.0096] [PMID]

7. Canton R, Coque TM. The CTX-M betalactamase pandemic. Curr Opin Microbiol. 2006;9(5):466-75.

[DOI:10.1016/j.mib.2006.08.011] [PMID]

8. Leylabadlo HE, Pourlak T, Bialvaei AZ, Aghazadeh M, Asgharzadeh M, Kafil HS. Extended-Spectrum Beta-Lactamase Producing Gram Negative Bacteria in Iran: A Review. Afr J Infect Dis. 2017;11(2):39-53. [DOI:10.21010/ajid.v11i2.6] [PMID] [PMCID]

9. El Fertas-Aissani R, Messai Y, Alouache S, Bakour R. Virulence profiles and antibiotic susceptibility patterns of Klebsiella pneumoniae strains isolated from different clinical specimens.
Pathol Biol (Paris). 2013;61(5):209-16. [DOI:10.1016/j.patbio.2012.10.004] [PMID]

10. Sedighi $M$, Zahedi Bialvaei $A$, Hamblin $M R$, Ohadi E, Asadi A, Halajzadeh $M$, et al. Therapeutic bacteria to combat cancer; current advances, challenges, and opportunities. Cancer Med. 2019;8(6):3167-81. [DOI:10.1002/cam4.2148] [PMID] [PMCID]

11. Barreto S, Zambrano M, Araque M. Phenotypic variations of susceptibility in Klebsiella pneumoniae strains of nosocomial origin and their association with biofilm formation. Investigacion clinica. 2009;50(2):221-9.

12. Schroll C, Barken KB, Krogfelt KA, Struve C. Role of type 1 and type 3 fimbriae in Klebsiella pneumoniae biofilm formation. BMC Microbiol. 2010;10(1):179. [DOI:10.1186/1471-2180-10179] [PMID] [PMCID]

13. Bartoloni A, Pallecchi L, Benedetti M, Fernandez C, Vallejos $Y$, Guzman E, et al. Multidrugresistant commensal Escherichia coli in children, Peru and Bolivia. Emerg Infect Dis. 2006;12(6):907-13.

[DOI:10.3201/eid1206.051258] [PMID] [PMCID]

14. Shivaee A, Mirshekar M. Association between ESBLs Genes and Quinolone Resistance in Uropathogenic Escherichia coli Isolated from Patients with Urinary Tract Infection. Infection Epidemiology and Microbiology. 2019;5(1):1523.

15. Donskey CJ. Antibiotic regimens and intestinal colonization with antibiotic-resistant gramnegative bacilli. Clin Infect Dis. 2006;43 Suppl 2(Supplement_2):S62-9. [DOI:10.1086/504481] [PMID]

16. Reddy P, Malczynski M, Obias A, Reiner S, Jin N, Huang J, et al. Screening for extended-spectrum $\beta$-lactamase-producing Enterobacteriaceae among high-risk patients and rates of subsequent bacteremia. Clinical infectious diseases. 2007;45(7):846-52. [DOI:10.1086/521260] [PMID]

17. Najjuka CF, Kateete DP, Kajumbula HM, Joloba ML, Essack SY. Antimicrobial susceptibility profiles of Escherichia coli and Klebsiella pneumoniae isolated from outpatients in urban and rural districts of Uganda. BMC Res Notes. 2016;9(1):235. [DOI:10.1186/s13104-016-20498] [PMID] [PMCID]

18. Najar Peerayeh S, Eslami M, Memaryani M, Siadat SD. High Prevalence of bla CTX-M-1 
Group Extended-Spectrum $\beta$-lactamase Genes in Escherichia coli Isolates From Tehran. Jundishapur Journal of Microbiology. 2013;6(7) :e6863. [DOI:10.5812/jjm.6863]

19. Bialvaei $A Z$, Pourlak $T$, Aghamali $M$, Asgharzadeh M, Gholizadeh P, Kafil HS. The prevalence of CTX-M-15 extended-spectrum $\beta$ lactamases among Salmonella spp. and Shigella spp. isolated from three Iranian hospitals. European Journal of Microbiology and Immunology. 2017;7(2):133-7.

[DOI:10.1556/1886.2017.00004] [PMID] [PMCID]

20. Nakamura A, Komatsu M, Noguchi N, Ohno Y, Hashimoto $E$, Matsutani $H$, et al. Analysis of molecular epidemiologic characteristics of extended-spectrum beta-lactamase (ESBL)producing Escherichia coli colonizing feces in hospital patients and community dwellers in a Japanese city. J Infect Chemother. 2016;22(2): 102-7. [DOI:10.1016/j.jiac.2015.11.001] [PMID]

21. Luvsansharav UO, Hirai I, Niki M, Sasaki T, Makimoto K, Komalamisra C, et al. Analysis of risk factors for a high prevalence of extendedspectrum \{beta\}-lactamase-producing Enterobacteriaceae in asymptomatic individuals in rural Thailand. J Med Microbiol. 2011;60(Pt 5):619-24.

[DOI:10.1099/jmm.0.026955-0] [PMID]

22. Li B, Sun JY, Liu QZ, Han LZ, Huang XH, Ni YX. High prevalence of CTX-M beta-lactamases in faecal Escherichia coli strains from healthy humans in Fuzhou, China. Scand J Infect Dis. 2011;43(3):170-4.

[DOI:10.3109/00365548.2010.538856] [PMID]

23. Mansury D, Motamedifar M, Sarvari J, Shirazi B, Khaledi A. Antibiotic susceptibility pattern and identification of extended spectrum betalactamases (ESBLs) in clinical isolates of Klebsiella pneumoniae from Shiraz, Iran. Iran J Microbiol. 2016;8(1):55-61.
24. asadpour nn. Frequency of Multidrug Resistant Beta Lactamase Producer Klebsiella Pneumoniae in Urinary Tract Infections in Rasht. Journal of Ilam University of Medical Sciences. 2017;25(2):82-90. [DOI:10.29252/sjimu.25.2.82]

25. Joo EJ, Kim SJ, Baek M, Choi Y, Seo J, Yeom JS, et al. Fecal Carriage of Antimicrobial-Resistant Enterobacteriaceae in Healthy Korean Adults. J Microbiol Biotechnol. 2018;28(7):1178-84. [DOI:10.4014/jmb.1801.12060] [PMID]

26. Lu B, Zhou H, Zhang X, Qu M, Huang $Y$, Wang Q. Molecular characterization of Klebsiella pneumoniae isolates from stool specimens of outpatients in sentinel hospitals Beijing, China, 2010-2015. Gut Pathog. 2017;9(1):39. [PMID] [DOI:10.1186/s13099-017-0188-7] [PMCID]

27. Candan ED, Aksoz N. Klebsiella pneumoniae: characteristics of carbapenem resistance and virulence factors. Acta Biochim Pol. 2015;62(4) :867-74. [DOI:10.18388/abp.2015 1148] [PMID]

28. Rodriguez-Navarro J, Miro E, Brown-Jaque $M$, Hurtado JC, Moreno A, Muniesa $M$, et al. Comparison of Commensal and Clinical Isolates for Diversity of Plasmids in Escherichia coli and Klebsiella pneumoniae. Antimicrob Agents Chemother. 2020;64(5). [DOI:10.1128/AAC.02064-19] [PMID] [PMCID]

29. Fu L, Huang $M$, Zhang $X$, Yang $X$, Liu $Y$, Zhang L, et al. Frequency of virulence factors in high biofilm formation blaKPC-2 producing Klebsiella pneumoniae strains from hospitals. Microb Pathog. 2018;116:168-72.

[DOI:10.1016/i.micpath.2018.01.030] [PMID]

30. Hossieni SE, Amini A, Soltanmoradi $H$, Ebrahimzadeh Namvar A. Frequency of fimH, magA and rmpA Genes among Klebsiella pneumoniae Isolates in Hospitalized Patients in Babol, Iran. Avicenna J Clin Med. 2018;25 (2):121-6. [DOI:10.21859/ajcm.25.2.121] 